\title{
THE ADVERSE EFFECT OF STEEL PARTICLE CONTAMINANTS ON FATIGUE LIFE OF GREASE LUBRICATED BALL BEARINGS
}

\author{
Stathis, A., Th. Costopoulos, D. Koulocheris and K. Raptis \\ School of Mechanical Engineering, National Technical University of Athens, \\ Iroon Polytexneiou 9, Athens 15780, Greece
}

Received 2014-05-16; Revised 2014-07-11; Accepted 2014-07-14

\begin{abstract}
The rating life of ball bearings is reduced when hard particle contaminants are present in the lubricant. Usually, this life reduction is taken into account in the calculation of modified rating life by using the contamination factor through a general characterization of the lubrication conditions. However, the impact of contaminant's variables such as size, hardness and concentration level has to be specified in detail. This need is resolved by the present work, where greases contaminated with hard steel particles of different sizes are tested with the purpose of finding a pattern in the relationship between steel particle sizes and the progress of wear inside the bearings. A laboratory rig is utilized for these tests and vibration analysis is performed to estimate the condition and the residual life of the bearings. After the tests, optical inspections performed in a stereoscope verify the predictions of vibration analyses. It was found that large contaminating particles, after their initial deformation, produce high stresses and therefore higher wear of the bearings and that the wear mechanism is closely related to the interruption of the lubricating film in such a way that local overheating caused point melting and adhesion of the particles adhered on the raceways. In case of grease contaminated with steel particles, vibration analysis can indicate the severity of wear and monitor its progress. From the conducted tests of the present work it is proved that the size of the contaminant particles affect strongly the wear process in such a way that the larger steel particle contaminants cause greater damage to the bearing. The vibration levels were higher and the damage was greater as particle size increased. It is difficult to establish an equation that describes and quantifies the wear progress involving all the parameters of size and concentration levels of the steel contaminant particles due to the stochastic nature of the wear mechanisms and therefore presently a statistical approach of the wear and the residual life expectancy seems to be more practical. The collection of a large number of experimental results is underway.
\end{abstract}

Keywords: Bearings, Fatigue, Wear, Contaminants, Measurements

\section{INTRODUCTION}

Rolling element bearings are critical components of many modern engines and machinery. When bearings have been chosen correctly, handled, installed and maintained properly, their service life can be well predicted from their basic rating life $\mathrm{L}_{10}$ as it is calculated by their manufacturer. Usually the operating conditions are different from the ideal conditions on which the $\mathrm{L}_{10}$ life is based. In order to take into account these different operating conditions, the International Standard (ISO, 2007) has moved towards a system approach of the bearing and has introduced the modified rating life $\mathrm{L}_{\mathrm{nm}}$ which is based on

Corresponding Author: Th. Costopoulos, School of Mechanical Engineering, National Technical University of Athens, Iroon Polytexneiou 9, Athens 15780, Greece, Tel.:+302107723477, Fax: +302107721523 
the $\mathrm{L}_{10}$ life, the reliability modification factor $\mathrm{a}_{1}$ and the modification factor $\alpha_{\text {ISO }}$ which is a function of lubricating conditions, lubricant contamination, operating temperature and fitting stresses.

Most of the largest bearing manufacturers state that lubricant contamination is the major cause of bearing failure before they reach their rated life. Lubricant cleanliness is taken into account when calculating the rating life. The classification of lubricant cleanliness is based on the ISO 4406: 1999 Cleanliness code which is limited in filtrated oil lubrication systems. For grease lubricated bearings, which have a large market share, an equivalent grease cleanliness classification has not been established in detail. Other aspects regarding the nature of particle contaminants such as size, hardness, brittleness and concentration levels have been investigated by researchers but they have not been quantified, as in similar studies (Chaabene et al., 2013).

In this study we experimentally evaluate vibration signal analysis methods for bearings under different lubricant contamination conditions which cause accelerated wear. Self-aligned, double row, ball bearings lubricated with hard steel particle pre-contaminated grease of two different particle sizes were tested. Vibration analysis is performed in the time and in the frequency domains in order to evaluate the accuracy of each indicator under these operating conditions and lubrication. At the end of the experiments the vibration analyses findings are compared with optical inspections of the bearings.

\subsection{Basic Rating Life of Rolling Element Bearings}

During their operating life, bearings are carrying loads which cause variable stresses to the contact surfaces. These Hertzian contact stresses are the main cause of fatigue, determining the useful operating life. This service life of rolling element bearings can be estimated based on the Weibull distribution and its application on bearings. Based on Weibull's theory (Palmgren and Lundberg, 1947) proposed that for a given probability $\mathrm{n}$, the service life of bearing can be calculated from the equation below Equation 1:

$$
L_{n}=\left(\frac{Q_{c}}{Q}\right) p
$$

Where:

$L_{n}=$ Basic rating life (with probability $n$ )

$Q_{c}=$ Basic dynamic load

$Q=$ Actual load

$p=$ Constant
Constant $\mathrm{p}$ is a function of the three constants $c, e$, $h$, regarding maximum shear stress exponents, Weibull slope and the type of the bearing. Several functions which correlate these constants have been proposed by (Harris and Kotzalas, 2006; Zaretsky et al., 2000), based on different assumptions of the importance and the influence of each one. Regardless of the adopted theory, constant $\mathrm{p}$ has been experimentally approximated to the values 3 for ball bearings and 10/3 for roller bearings. Usually, the basic rating life $\mathrm{L}_{10}$ is used, expressing the expected life with $90 \%$ reliability. In addition, the basic dynamic radial $\mathrm{C}_{\mathrm{r}}$ or axial $\mathrm{C}_{\mathrm{a}}$ load is used in conjunction with the dynamic equivalent radial $\mathrm{P}_{\mathrm{r}}$ or axial $\mathrm{P}_{\mathrm{a}}$ load.

In practice, rolling element bearings show longer service lives than their basic rated $\mathrm{L}_{10}$ life when they operate under normal conditions. On the other hand, service lives are shorter when the operating conditions and especially temperature and lubricating conditions are worse. The need for calculating the expected service life under realistic, non-normal conditions led to the introduction of the modified rating life $\mathrm{L}_{\mathrm{nm}}$ which takes into account these operating conditions and also provides results for probabilities different from $90 \%$. According to (ISO, 2007), the modified rating life $\mathrm{L}_{\mathrm{nm}}$ of the bearings can be calculated from the equation below Equation 2:

$L_{n m}=\alpha_{1} \times \alpha_{I S O} \times L_{10}$

Where:

$\alpha_{1}=$ Life modification factor for reliability

$\alpha_{I S O}=$ Life modification factor, based on a systems approach of life calculation

The life modification factor $\alpha_{\text {ISO }}$ is a function of the bearings' operating conditions as it is shown in Equation 3:

$\alpha_{I S O}=f\left(\frac{e_{c}, C_{u}}{P}, \kappa\right)$

Where:

$e_{c}=$ Contamination factor

$C_{u}=$ Fatigue load limit

$P=$ Dynamic equivalent load

$\kappa=$ Viscosity ratio of the lubricant

The contamination factor $\mathrm{e}_{\mathrm{c}}$ can be estimated based on some rough, simple guidelines regarding the lubrication conditions. The values of the factor have been found experimentally and they are given in relevant 
tables. Generally, life reduction caused by solid particles in the lubricant film is dependent on:

- Type, size, hardness and quantity of the particles

- Lubricant film thickness and viscosity

- Bearing size and clearances

The researches of (Godet, 1984; Nikas et al., 1998) on bearings' wear due to contaminants point to several possible mechanisms of wear. In terms of contaminant sizes (Maru et al., 2007; Dwyer-Joyce, 1999) state that the critical size is in the order of the lubrication film thickness as particles entrapped in the contact zone are causing local oil starvation, increased heating and material melting, while others report that when particles larger than the oil film thickness enter the contact zone, they cause stress peaks and permanent indentations in the raceway as they are over rolled. These stress peaks lead to a reduced life of the rolling bearing due to fatigue.

Usually the contaminants are larger than the typical lubricant film but rather small compared with the contact bodies. As they enter the contact zone it is difficult to move the bearing elements apart, so they are deformed. Ductile contaminants are rolled into pellets and brittle contaminants are crushed into fragments, as shown in Fig. 1, which is adapted from (Nikas, 2010). According to (Dwyer-Joyce, 2005) the damage to the contact surfaces is controlled by the size of these deformed particles which in turn depends on the hardness of the ductile particles and the toughness of the brittle particles.

When ductile particles enter the contact zone they deform elastically or elastoplastically in order to accommodate between the contact surfaces. Generally, denting due to high stresses is associated with the hardness of the contaminant and the hardness of the contact surfaces. Various equations have been proposed by (Dwyer-Joyce et al., 1990), regarding particles softer or harder than the contact surfaces, correlating possible denting with the relevant hardness. Depending on their hardness the rather soft particles are extruded resulting in high friction and contact pressures leading to adhesive wear. Sayles (1995) found that high friction produces frictional heating and flash temperatures of a few hundred degrees Celsius. Harder particles are responsible for abrasive wear through the two major mechanisms, the two-body wear and the three-body wear. Hard ductile particles tend to imbed the softer surfaces and when they do so, the embedded particles are scratching the contact surfaces when sliding occurs. High frictional temperatures are also present and often phenomena similar to those described in adhesive wear occur.

\subsection{Vibration Signal Analysis on Rolling Element Bearings}

Rolling element bearings produce mechanical vibrations and noise as they rotate. When faults are present, these vibrations are increased as the motion of the rolling elements is more disturbed. These faults can be minor cracks or even spalls due to fatigue, denting, scuffing, scoring, wear, or any other kind of deformation of the contact surfaces. The vibration signal can be further processed in the time and in the frequency domain.

In time domain, data are processed with statistical and arithmetical methods. The most common values that are measured or calculated are (Karacay and Akturk, 2009; Niu et al., 2005):

- The minimum and the maximum amplitude

- The peak count

- Mean $\mu$ and standard deviation $\sigma$

- Root Mean Square (RMS)

- The crest factor (peak to rms)

- Statistical moments of higher order such as skewness $\mathrm{S}$ and kurtosis $\mathrm{K}$

Data which have been recorded in time domain can easily be represented in the frequency domain with the use of a Fourier transformation. The most common Fourier transform method is the Discrete Time Fourier Transform (DTFT) which is calculated efficiently with the use of a Fast Fourier Transform (FFT) algorithm. In frequency domain various types of analyses can be performed such as spectral analysis, cepstrum analysis or bispectral analysis, (Zotos and Costopoulos, 2009).

Certain faults and malfunctions exhibit signal peaks in characteristic frequencies. Faults in rolling element bearings produce signals in frequencies which depend on the geometrical characteristics of the bearing and the rotation frequency $f$.

Most studies, (Raptis et al., 2011; Wongchai et al., 2013) regard experimental setups in laboratory conditions with minimum distortion and low noise to affect the measured signals. In most real life situations things are more complicated, (Zotos and Costopoulos, 2008). Vibrations and noise are introduced into the signal due to angular and axial misalignment, shaft imbalance, improper support and fixings, electrical noise, transducer position, load variation. 


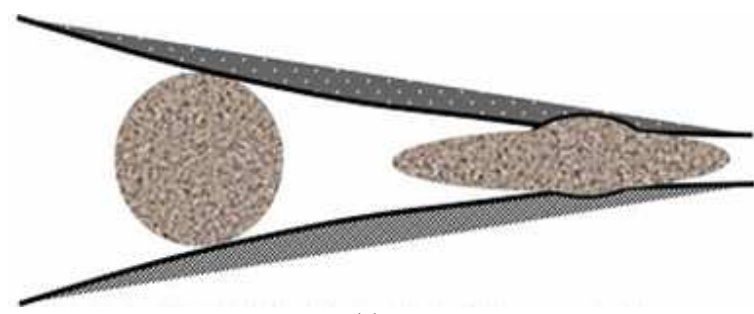

(a)

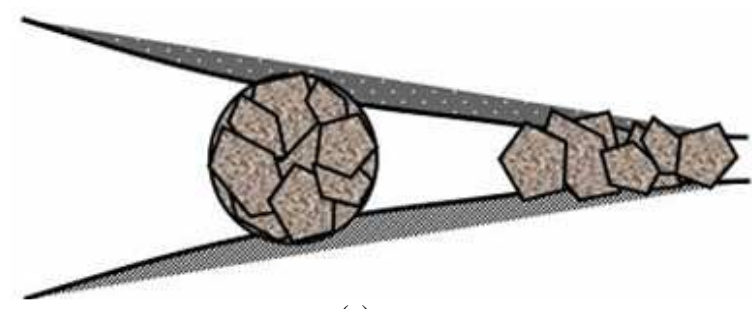

(c)

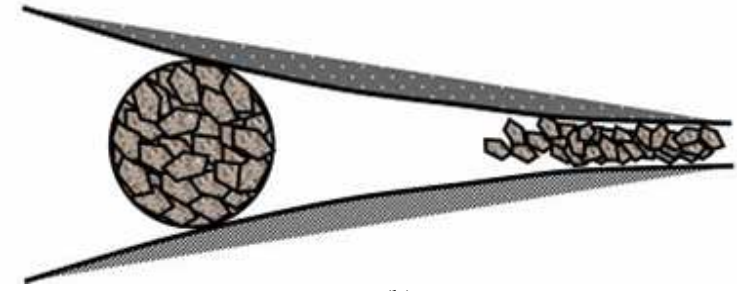

(b)

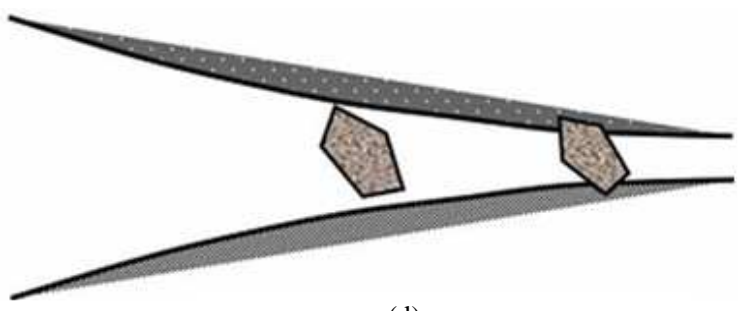

(d)

Fig. 1. Particle behavior as it enters the contact zone in relation with its characteristics, (Nikas, 2010); (a) A ductile particle deforms in the inlet zone and becomes a platelet as it is compressed. (b) A low-toughness brittle particle fractures early in the inlet zone and produces small fragments that may imbed the contact surface. (c) A high-toughness brittle particle fractures late in the inlet zone and produces large fragments that imbed the contact surfaces. (d) A small, tough particle behaves rigidly

These parameters are limiting the use of time domain analysis as the magnitude of the measured signal is dominated mostly by noise rather than the measured characteristic. In these situations frequency domain analysis seems to present more useful results.

\section{EXPERIMENTS}

\subsection{Experimental Setup}

The setup simulates a common industrial arrangement where a shaft is radially loaded on its free end. The schematic of the bearing test rig on which the experiments are carried out is shown in Fig. 2, (Zotos and Costopoulos, 2009). Three different types of bearings are used, having the same bore diameter. This selection has been made in order to use in each housing bearings with different characteristic frequencies and as a result to have a clearer indication about the source of the measured vibration signal. All bearings have conical internal rings with a bore diameter of $35 \mathrm{~mm}$ and they are mounted on the shaft with the use of proper adapter sleeves.

Two Kistler type 8792A25T three-axial accelerometers are mounted with magnets on the top of the two plumper type housings. Visualization and processing of the signals is made through HBM CATMAN software installed on a Laptop PC. The naming of the axes is following the naming of the accelerometer's axes which is: $\mathrm{X}$ for the axis of the shaft, $\mathrm{z}$ for the axis of the load direction and $\mathrm{y}$ for the axis vertical to the plane xz. Also, a K-type thermometer was used in order to measure the shaft, bearings and housings temperatures and the ambient temperature.

\subsection{Pre-Contaminated Grease}

The pre-contaminated grease was made by mixing solid contaminant particles with clean grease. The grease used was SKF LGMT3 mineral oil based, lithium soap thickened grease with base oil viscosity of 120-130 $\mathrm{mm}^{2} / \mathrm{s}$ at $40^{\circ} \mathrm{C}$ and $12 \mathrm{~mm}^{2} / \mathrm{s}$ at $100^{\circ} \mathrm{C}$. The solid particles used as contaminants were corundum particles with a hardness of about $2000 \mathrm{HV}$. Two samples with different particle size were used as shown on Table 1.

In order to achieve similar volumetric concentration of particles in the contaminated grease, a quantity of 0,75 $\mathrm{cm}^{3}$ of particles was mixed with 50 grams of clean grease. Most of the quantity used remains in the housing and only a small amount of grease is recirculating. The actual amount of particles which enter the contact zone is only a fraction of the used quantity.

\subsection{Procedure of Experimentation}

Two tests were conducted using the above configuration. At the beginning of the experiments the rear housing and the bearing was cleaned from the preservation oil and then the bearing was filled with clean grease. 


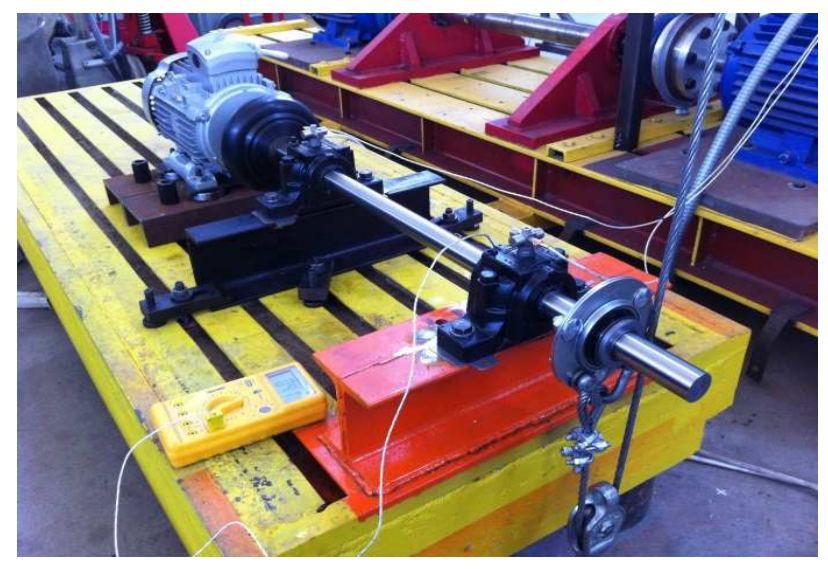

Fig. 2. Photo of the test rig

Table 1. Material and size table of the used contaminants

\begin{tabular}{lllll}
\hline Test & Material & Mesh size & $\begin{array}{l}\text { Particle } \\
\text { size }(\mu \mathrm{m})\end{array}$ & $\begin{array}{l}\text { Average } \\
\text { size }(\mu \mathrm{m})\end{array}$ \\
\hline 1 & Steel & $180-220$ & $62-73$ & 68 \\
2 & Steel & $80-120$ & $105-177$ & 141 \\
\hline
\end{tabular}

The same procedure has been followed for the front housing using one of the grease mixtures described above.

A load of $2800 \mathrm{~N}$ was applied to the flanged housing resulting in a load of $3500 \mathrm{~N}$ at the front bearing and a load of $700 \mathrm{~N}$ at the rear bearing. The motor and shaft rotation speed was set to $2400 \mathrm{rpm}(40 \mathrm{~Hz})$. The signal from six channels was recorded, corresponding to the three axes of each of the two accelerometers. The sampling rate was set to 2400 samples per second (sampling frequency) for each channel.

The duration of the experiments was $14 \mathrm{~h}$ for each test, representing about 2 millions of revolutions. After the completion of each test, the front housing was opened and cleaned from the remaining grease. The bearing was dismantled and its parts were cleaned from the grease. After cleaning, the parts of each bearing were subjected to optical inspection with a LEICA stereoscope.

During the tests, the vibration signals from the accelerometers were monitored in real time and recorded all data were recorded and saved in. BIN type file format which can be further processed with Matlab software.

\section{DATA AND CALCULATIONS}

According to (ISO, 2007), the $\mathrm{L}_{\mathrm{nm}}$ life of the tested bearings can be calculated from the Equations 1 and 2 . For the applied load the $\mathrm{L}_{10}$ life of each bearing is calculated based on the manufacturer's basic dynamic load. The results are given in Table 2 .

For the modified basic rating life $\mathrm{L}_{\mathrm{nm}}$ the life modification factor for reliability $\alpha_{1}$ equals to 1 for a $90 \%$ reliability. The life modification factor for system approach $\alpha_{\text {Iso }}$ depends on the contamination factor $e_{c}$, the fatigue load limit $C_{u}$, the actual load $P$ and the viscosity ratio $\kappa$.

The contamination factor $e_{c}$ can be estimated from the given guidelines. The bearing's pitch diameter $d$ is about $54 \mathrm{~mm}$ and the viscosity ratio $\kappa$ of the grease used at the test temperature of the bearings $\left(65^{\circ} \mathrm{C}\right)$ is about 3.5. For grease lubrication under high cleanliness, $e_{c}$ can be as high as 0.8 for the dimensions of the tested bearing (Pitch diameter $\mathrm{d} \approx 54 \mathrm{~mm}$ ) and for the viscosity ratio $\kappa$ of 3.5. In severe contamination conditions, $e_{c}$ is in the range of 0.05 and in very severe contamination it tends to zero. The bearings manufacturer provides also an advanced method of calculating the rating life according to the size of the contaminants and their hardness. The results from these calculations are shown on Table 3 and 4.

The characteristic bearing potential frequencies of each bearing can be calculated with the use of Equations 9 to 12 . The dimensions of the bearings are required but instead, the manufacturer provides these values according to the operation speed. For the rotational speed of $2,400 \mathrm{rpm}(40 \mathrm{~Hz})$ and for a contact angle of $0^{\circ}$ the characteristic frequencies are given in Table 5.

Table 2. Loads and basic rating life calculations for the all testing rig's bearings

\begin{tabular}{|c|c|c|c|}
\hline & $\begin{array}{l}\text { SKF } 1207 \\
\text { EKTN9 } \\
\text { 'front' }\end{array}$ & $\begin{array}{l}\text { SKF } 2207 \\
\text { EKTN9 } \\
\text { 'rear' }\end{array}$ & $\begin{array}{l}\text { SKF YSA } \\
207-2 \text { FK } \\
\text { 'load' }\end{array}$ \\
\hline $\begin{array}{l}\text { Basic } \\
\text { dynamic load } \\
\text { Maximum }\end{array}$ & $19,000 \mathrm{~N}$ & $30,700 \mathrm{~N}$ & $25,500 \mathrm{~N}$ \\
\hline allowed static load & $6,000 \mathrm{~N}$ & $8,800 \mathrm{~N}$ & $15,300 \mathrm{~N}$ \\
\hline $\begin{array}{l}\text { Actual load } \\
\mathrm{L}_{10} \text { in }\end{array}$ & $3,500 \mathrm{~N}$ & $700 \mathrm{~N}$ & $2,800 \mathrm{~N}$ \\
\hline $\begin{array}{l}\text { revolutions } \\
\mathrm{L}_{10} \text { in hours } \\
\text { (at } 2400 \mathrm{rpm} \text { ) }\end{array}$ & $160 \times 10^{6}$ & $84,400 \times 10^{6}$ & $760 \times 10^{6}$ \\
\hline
\end{tabular}

Table 3. Modified rating life calculations for various lubricant conditions for the tested bearing

\begin{tabular}{llll}
\hline Lubricant condition & $\mathrm{e}_{\mathrm{c}}$ & $\alpha_{\mathrm{ISO}}$ & $\mathrm{L}_{10 \mathrm{~m}}$ \\
\hline High cleanliness & 0.80 & 3.80 & 4,240 \\
Normal cleanliness & 0.60 & 2.60 & 2,850 \\
Slight to typical & & & \\
contamination & 0.18 & 0.77 & 856 \\
Severe contamination & 0.05 & 0.36 & 400 \\
Very severe contamination & 0.00 & 0.10 & 111 \\
\hline
\end{tabular}


Table 4. Modified rating life calculations according to SKF

\begin{tabular}{llcccc}
\hline Test & $\begin{array}{l}\text { Particle } \\
\text { hardness }\end{array}$ & $\begin{array}{l}\text { Average } \\
\text { size }(\mu \mathrm{m})\end{array}$ & $\mathrm{e}_{\mathrm{c}}$ & $\alpha_{\mathrm{ISO}}$ & $\mathrm{L}_{10 \mathrm{~m}}$ \\
\hline 1 & $700 \mathrm{HV}$ & 68 & 0.130 & 0.62 & 688 \\
2 & $700 \mathrm{HV}$ & 141 & 0.042 & 0.33 & 371 \\
\hline
\end{tabular}

Table 5. Frequencies of potential damage in the tested ball bearings

\begin{tabular}{llll}
\hline & $\begin{array}{l}\text { SKF 1207 } \\
\text { EKTN9 } \\
\text { 'front' }\end{array}$ & $\begin{array}{l}\text { SKF 2207 } \\
\text { EKTN9 } \\
\text { 'rear' }\end{array}$ & $\begin{array}{l}\text { SKF YSA } \\
\text { 207-2FK } \\
\text { 'load' }\end{array}$ \\
\hline$f$ & $40.0 \mathrm{~Hz}$ & $40.0 \mathrm{~Hz}$ & $40.0 \mathrm{~Hz}$ \\
$f_{c}$ & $16.8 \mathrm{~Hz}$ & $15.8 \mathrm{~Hz}$ & $15.8 \mathrm{~Hz}$ \\
$f_{\text {bpfo }}$ & $251.0 \mathrm{~Hz}$ & $190.0 \mathrm{~Hz}$ & $143.0 \mathrm{~Hz}$ \\
$f_{\text {bpfi }}$ & $349.0 \mathrm{~Hz}$ & $290.0 \mathrm{~Hz}$ & $217.0 \mathrm{~Hz}$ \\
$f_{r}$ & $119.0 \mathrm{~Hz}$ & $89.1 \mathrm{~Hz}$ & $92.1 \mathrm{~Hz}$ \\
$2 x f_{r}$ & $238.0 \mathrm{~Hz}$ & $178.0 \mathrm{~Hz}$ & $184.0 \mathrm{~Hz}$ \\
\hline
\end{tabular}

\section{EXPERIMENTAL RESULTS}

The measured signals are processed in time domain and in frequency domain. The axes of greater importance are the $x$ axis, which is the axis of the shaft and represents the axial loads of the bearing and the $\mathrm{z}$ axis which is the axis of the applied radial load. The $y$ axis, which is the axis vertical to the applied load, shows similar trends to the others but with much lower signal amplitudes.

\subsection{Vibration Analysis in the Time Domain}

Due to the numerous sources of vibrations as various particles enter the loading zone and the randomness of their nature, the statistical variables of higher order such as skewness and kurtosis do not give any useful results. The importance of these variables is grater when a fault appears on a bearing running under normal conditions. In these situations, the aforementioned variables, which normally show small fluctuation, will change significantly. Such behavior has been successfully reported by other researchers when they created an artificial single point defect.

As it is shown in the plots of acceleration peaks and rms values in Fig. 3, the peak values of acceleration are significant higher when the larger particles are used. It seems that when particles with average size of $68 \mu \mathrm{m}$ are used the peaks are about $0.5 \mathrm{~g}$ or less on both the $\mathrm{x}$ and $\mathrm{z}$ but with the larger particles the amplitude is increased to about $7 \mathrm{~g}$ on the $\mathrm{x}$ axis and to an extreme of $50 \mathrm{~g}$ on the $\mathrm{z}$ axis (between 11 and $15 \mathrm{~h}$ of operation).
The rms value of the acceleration remains on the same levels during the tests. When the smaller contaminants are used, on the $\mathrm{z}$ axis, the rms value of acceleration is low too, with a value of less than $0.05 \mathrm{~g}$. When larger particles are used, the rms value of the acceleration on the $\mathrm{x}$ axis is higher with an average value of $0.15 \mathrm{~g}$ and with values up to $6 \mathrm{~g}$ at the time when the acceleration peaks encountered.

\subsection{Vibration Analysis in the Frequency Domain}

The vibration analysis in the time domain can show a malfunction of the bearing only when it is affecting the vibration levels. The exact source of this malfunction is unknown and only assumptions can be made. In our case, the source of the increased vibrations could not be identified only from the vibration analysis results. Vibrations could be generated by particles entering randomly the contact zone, or by permanent deformations on the raceways. In the first case, vibrations do not follow a specific pattern, but in the second case the amplitude of vibrations on the bearings potential damage frequencies, shown on Table 5, is increased.

Processing the acquired data in the frequency domain, results in the identification of the true source of the vibrations and in the detection of possible faults. Frequency spectrum plots of the obtained data are created by implementing a fast Fourier transform in Matlab software environment. In order to reduce the spectral leakage and make the dominant frequencies easier to be identified, the power spectrum is used, where the outputs of the FFT are raised to the square.

In a similar way as in (Karim et al., 2014), frequency spectra plots of the tests have been created using five samples of each test data series as in Fig. 4. In the first test using smaller particle contaminants noticeable higher amplitude is occurring on both $\mathrm{x}$ and $\mathrm{z}$ axes, at the frequency of $251.5 \mathrm{~Hz}$, which is the bearing's potential damage frequency for the outer raceway.

In the other test, using larger steel particles, on the $\mathrm{x}$ axis peaks occur at the frequencies of 279.8 and 319.8 $\mathrm{Hz}$ (Fig. 5). Peaks at these frequencies occur due to the contact angle of the balls of the bearing which seems to be different than $0^{\circ}$. Thus, for a contact angle different than zero, the characteristic frequency for a potential fault on the outer raceway is higher than that shown on Table 5 and for a potential fault on the inner raceway is 
lower. On the $\mathrm{z}$ axis only at the beginning of the test there is a peak at the frequency of $39.81 \mathrm{~Hz}$ which is the shaft rotation frequency.

Notice that for the tested bearings (double row self-aligning ball bearings) the contact angles can be different for the inner and outer raceways as they have different shapes: The inner raceway has deep grooves and the outer raceway has an elliptical form. Also, the contact angles of each row might be slightly different due to the potential different alignment of the inner and outer raceway.

Other bearing characteristic frequencies can be identified when zooming close to the area of interest. The relatively small amplitudes show that no significant faults have occurred. In the test where the larger steel particles are used, the spectral analysis indicates that no significant fault has occurred despite the acceleration peaks and the high acceleration rms value measured in the time domain. It seems that the steel particles cause high levels of vibration but they do not causing severe surface deformation. Of course the high stresses, due to particles entering the contact zone, are expected to reduce the fatigue life of the bearing.

\subsection{Visual Inspection and Verification of Results}

After the completion of the tests, the bearings were dismantled and cleaned from the greases. The bearing elements and the faults on them were photographed with the use of a stereoscope and a digital camera attached to it, in a similar way with (Iskandarani, 2013). The findings from the visual inspections are conforming to the results of the vibration analyses.

On both bearings the rolling marks on the raceways can be seen, but no severe damage is visible with naked eye. Most of the damage is made on the plating of the outer raceway but no significant indentations or deformations exist except scratching and scoring as it can be seen in Fig. 6. The width of the affected contact zone is about $500 \mu \mathrm{m}$ for both tests. The width of the inner ring contact area is about $2 \mathrm{~mm}$, wider than the outer raceway's due to the different curving. On the inner ring the surface on the contact zone is dull and there is also some small scale pitting (Fig. 7).

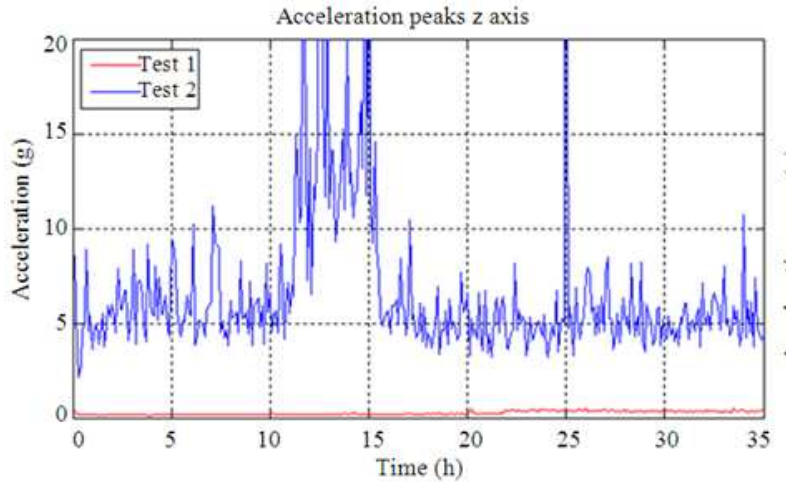

(a)

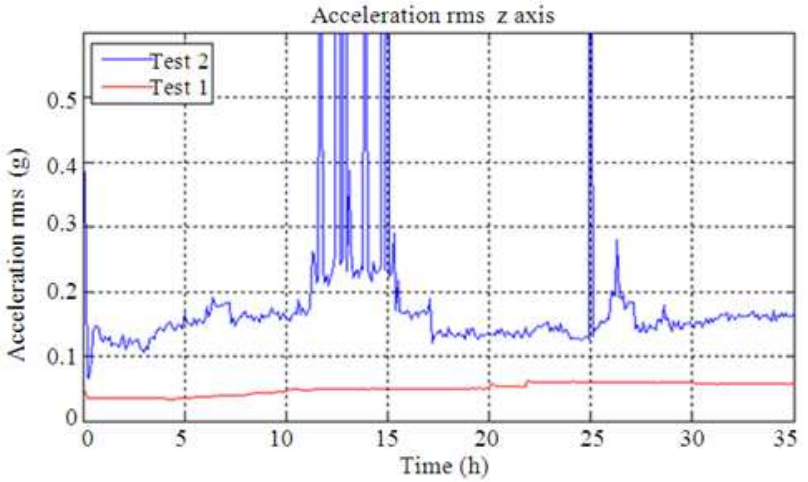

(b)

Fig. 3. Acceleration Peaks and RMS values on $\mathrm{z}$ axis using steel particle contaminants

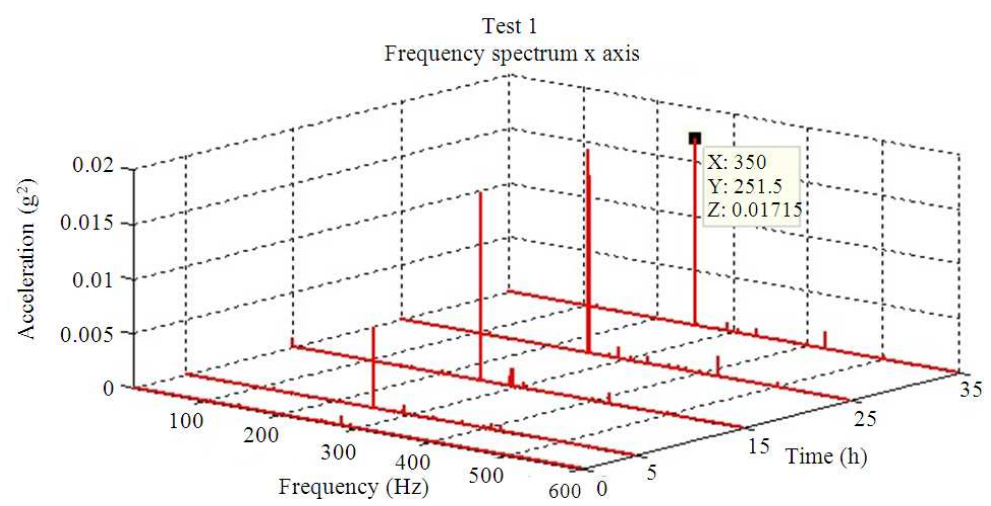

Fig. 4. Frequency spectra plots of the 1st test using steel particles with average size of $68 \mu \mathrm{m}$ 


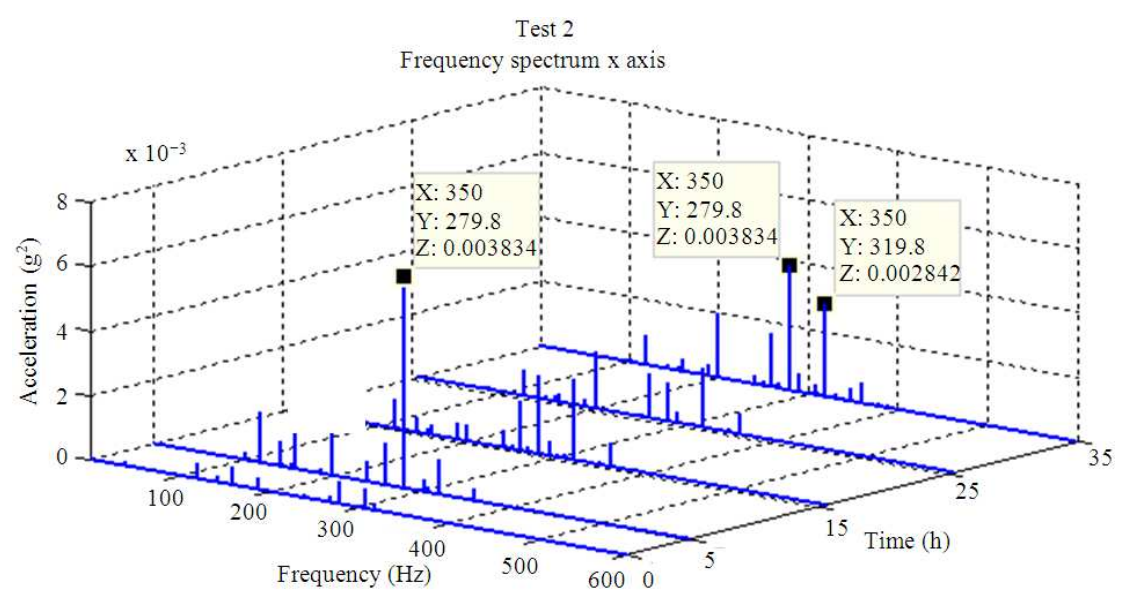

Fig. 5. Frequency spectra plots of the 2 nd test using steel particles with average size of $141 \mu \mathrm{m}$
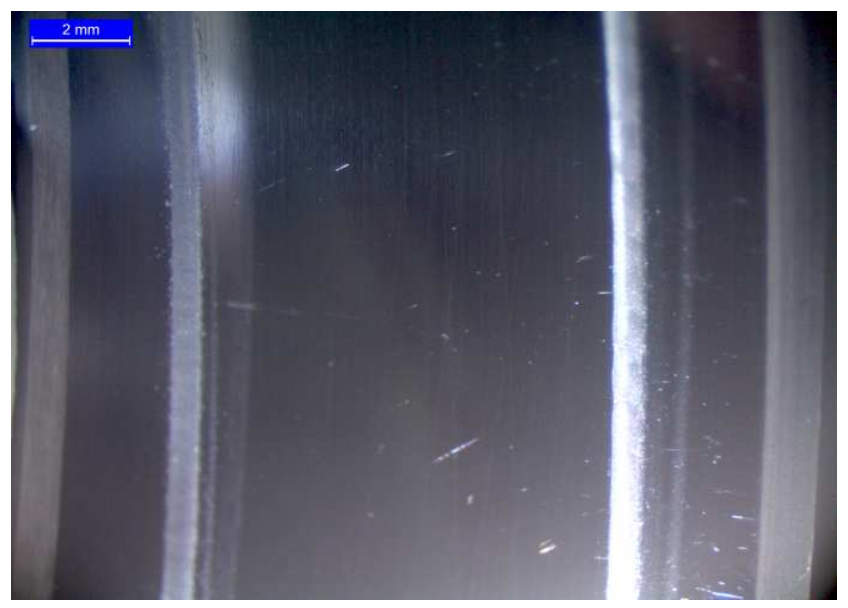

Fig. 6. Typical scratching and scoring on the contact surfaces of the outer raceways using grease contaminated with steel particles of average size $68 \mu \mathrm{m}$ (test 1)-notice the small wavelike pattern on the right raceway

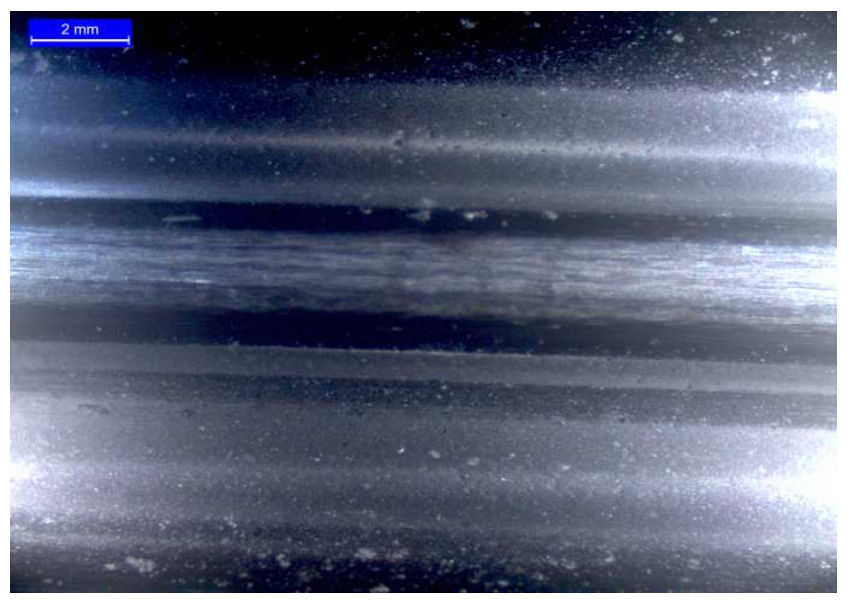

Fig. 7. Wear on the inner raceways with micro-pitting (test 2) 
When using strong magnification it can be seen that small metal particles are attached to the contact surface of the outer raceways (Fig. 8). As the contaminant size increases, the amount of these adhered particles is increasing and oxidation and burning marks are present in the center of the contact zone (Fig. 9).
Generally, as larger particles were used, the bearing seems to have rougher marks and the findings indicate that the severity of the damage is increasing. As the performance of the bearings has not change dramatically, it can be assumed that the damage after the test do not seem to be critical.

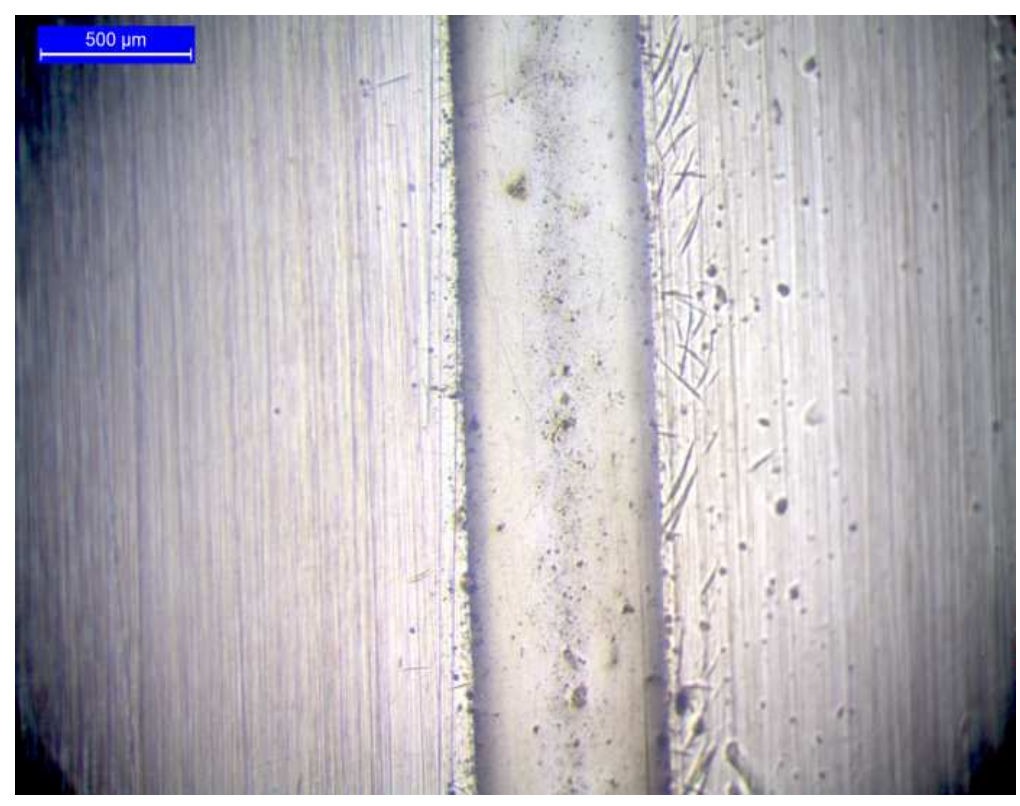

Fig. 8. Steel particle contaminants adhered or imbedded on the outer raceway (test 1)

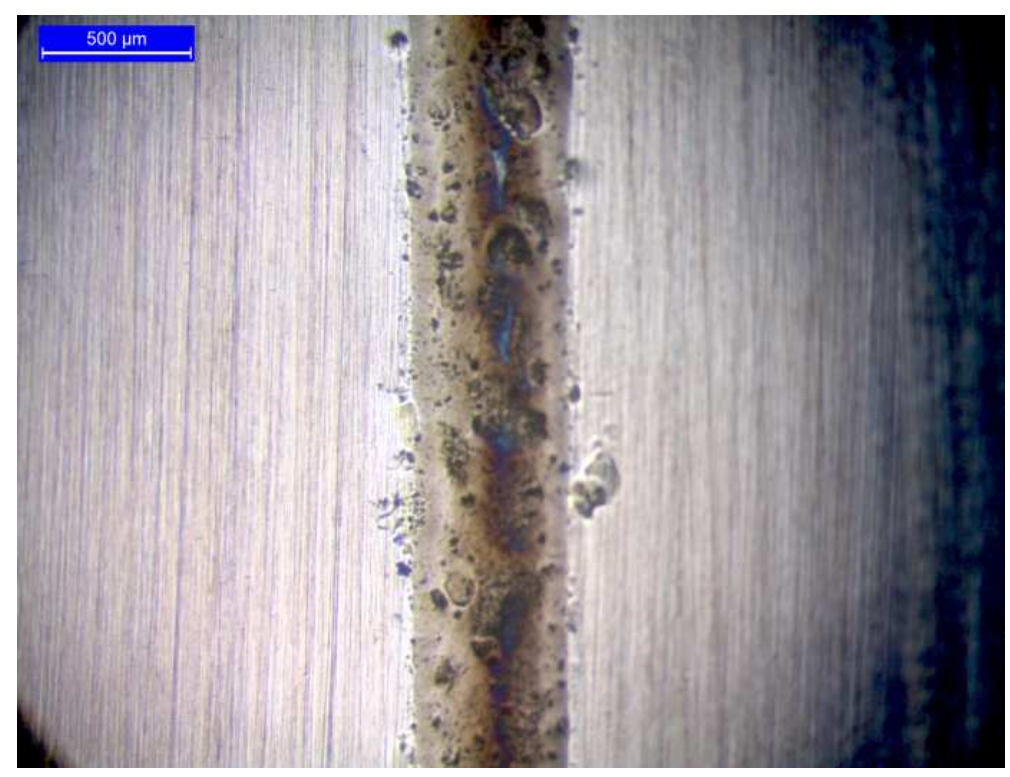

Fig. 9. Steel particle contaminants adhered on the outer raceway and oxidation marks due to local overheating and burning of the lubricant (test 2) 


\section{DISCUSSION}

Comparison of the present results with results of constructors of bearing SKF, TIMKEN, show that they correlate smoothly. They are inside the range of the predictions and they explain several arguments and difficult points otherwise unresolved. Vibration analysis in the time domain can give useful information about the overall performance of the bearing. As particles enter the contact zone they are deformed due to the high stresses. Ductile particles, like the steel particles used, are rolled over forming round flakes. Due to the vortexes of the lubricant, rolled-over particles recirculate and they can reenter the contact zone in a different position. The continuous rolling and the excessive heat produced cause some of the particles to melt and adhere to the contact area.

Generally, the vibration levels are increasing with larger particles as friction and plastic deformation phenomena are more intense. Also, the adhesion of some particles to the contact surfaces and their recirculation can explain why the vibration is not decreasing after the first run-in time.

In the frequency domain, (Karim et al., 2014). it seems that in the first test there is a small failure on the outer raceway. After the initial visual inspection it seemed that the wear in the second case was more severe and these peaks on the first test could not be explained. After careful visual inspection with the stereoscope from different view angles and different lighting, a small waviness in the outer raceway of the first test could be seen as in Fig. 10. These wave-like deformations were the cause of the peaks in the frequency spectrum. Notice that the Fourier transform adds all excitations on a specific frequency, regardless the different phase they might have.

\section{CONCLUSION}

Signal analysis has an increasingly important role as a tool for assisting predictive and preventive maintenance. When monitoring rolling element bearings, both analyses in the time domain and in the frequency domain can give useful results. The analysis in time domain can indicate if there is an abnormal operation of a bearing and show the trend of the amplitude increase. In the frequency domain, vibration analysis can indicate whether the increased vibrations are caused from a certain bearing defect or from external sources. The increase of the vibration amplitude on the characteristic frequencies of the bearing can also indicate the progress of that specific fault.

In case of grease contaminated with solid particles, vibration analysis can indicate the severity of wear and monitor its progress. From the conducted tests of the present work it is concluded that the size of the contaminant particles affect strongly the wear process. It is found that larger particles cause greater damage to the bearing. The vibration levels were higher and the damage was grater as particle size increased.

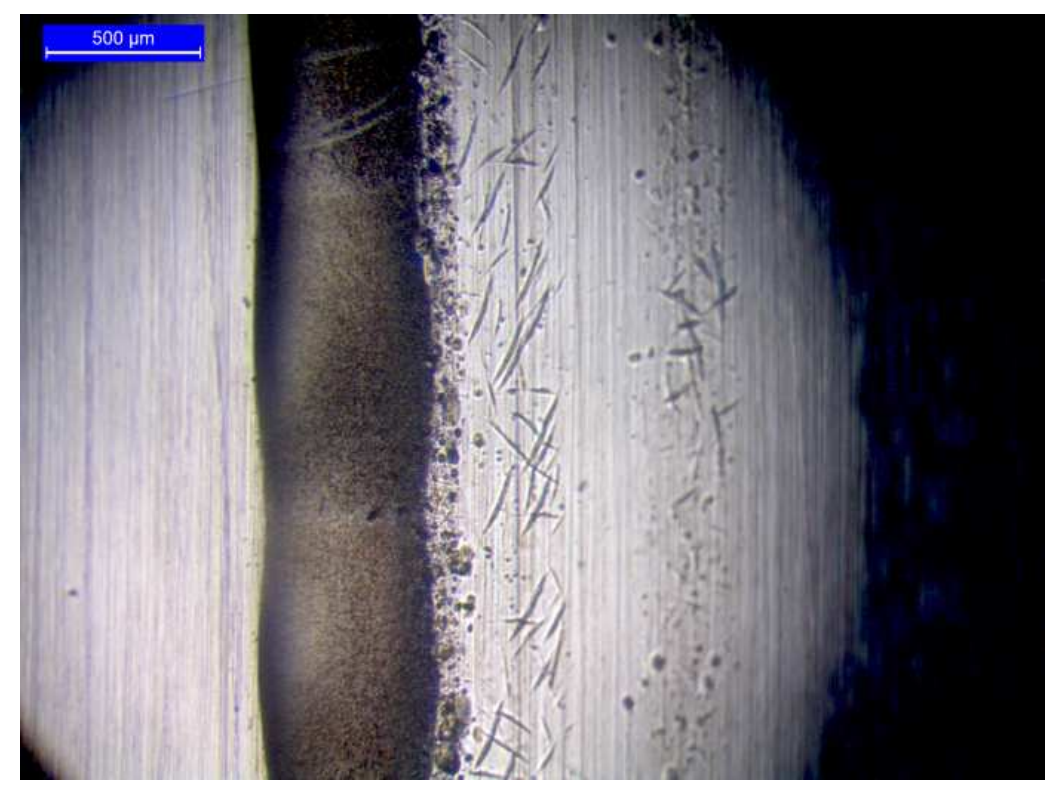

Fig. 10. Wave-like deformation on the outer raceway (test 1) 
The stochastic nature of the wear mechanisms, due to the large number of parameters of size and concentration levels of the steel contaminant particles, makes it difficult to establish an equation, like (NianChun et al., 2013), that describes and quantifies the wear progress. A statistical approach of the wear and the residual life expectancy seems to be more practical, (Huang et al., 2013; Jaoude and El-Tawil, 2013). The experimental team of the laboratory is working towards this purpose to collect the large number of experimental results which are necessary.

\section{ACKNOWLEDGMENT}

The present study was conducted in the facilities of the National Technical University of Athens, NTUA. The authors would like to thank the personnel of the Laboratories of this University for their assistance.

\section{REFERENCES}

Chaabene, A.B., M.F. Elkaroui and A. Sellami, 2013. Efficient design of a photovoltaic water pumping and treatment system. Am. J. Eng. Applied Sci., 6: 226232. DOI: 10.3844/ajeassp.2013.226.232

Dwyer-Joyce, R.S., J.C. Hamer, R.S. Sayles and E. Ioannides, 1990. Surface damage effects caused by debris in rolling bearing lubricants, with an emphasis on friable materials. Proceedings of the Institution of Mechanical Engineers Symposium on Rolling Element Bearings, (REB' 90), pp: 1-8.

Dwyer-Joyce, R.S., 1999. Predicting the abrasive wear of ball bearings by lubricant debris. Wear, 233: 692701. DOI: 10.1016/S0043-1648(99)00184-2

Dwyer-Joyce, R.S., 2005. The life cycle of a debris particle. Tribology Interface Eng. Series, 48: 681690. DOI: 10.1016/S0167-8922(05)80070-7

Godet, M., 1984. The third body approach: a mechanical view of wear. Wear, 100: 437-452. DOI: 10.1016/0043-1648(84)90025-5.

Harris, T.A. and M.N. Kotzalas, 2006. Advanced Concepts of Bearing Technology. 5th Edn., Illustrated, CRC Press, ISBN-10: 1420006584, pp: 368.

Huang, H.Z., L. He, Y. Liu, N.C. Xiao, Y.F. Li et al., 2013. Possibility and evidence-based reliability analysis and design optimization. Am. J. Eng. Applied Sci., 6: 95-136. DOI: 10.3844/ajeassp.2013.95.136
Iskandarani, M.Z., 2013. A new approach to damage detection in composite body structures using time compensated hyperspectral image analysis technique. Am. J. Applied Sci., 10: 123-130. DOI: 10.3844/ajassp.2013.123.130

ISO, 2007. ISO 281:2007, rolling bearings-dynamic load ratings and rating life. International Standardization for Organization.

Jaoude, A.A. and K. El-Tawil, 2013. Stochastic prognostic paradigm for petrochemical pipelines subject to fatigue. Am. J. Eng. Applied Sci., 6: 145160. DOI: 10.3844 /ajeassp.2013.145.160

Karacay, T. and N. Akturk, 2009. Experimental diagnostics of ball bearings using statistical and spectral methods. Tribol. Int., 42: 836-843. DOI: 10.1016/j.triboint.2008.11.003

Karim, B.A., B. Slimane, H.A. Elias, B. Nadir and K. Samir, 2014. Investigation on the diagnosis of simple and combines mechanical faults in asynchronous motor based electric drives. Am. J. Applied Sci., 11: 994-1004. DOI: 10.3844/ajassp.2014.994.1004

Maru, M.M., R.S. Castillo and L.R. Padovese, 2007. Study of solid contamination in ball bearings through vibration and wear analyses. Tribol. Int., 40: 433-440. DOI: 10.1016/j.triboint.2006.04.007

Nian-Chun, L., L. Xin-Gang, C. Yun-Hong and C. Jin, 2013. Dynamic propagation problems of mode III semi-infinite crack. Am. J. Eng. Applied Sci., 6: 241-251. DOI: 10.3844/ajeassp.2013.241.251

Nikas, G.K., R.S. Sayles and E. loannides, 1998. Effects of debris particles in sliding/rolling E. elastohydrodynamic contacts. J. Eng. Tribol., 212: 333-342. DOI: 10.1243/1350650981542146

Nikas, G.K., 2010. A state-of-the-art review on the effects of particulate contamination and related topics in machine-element contacts. J. Eng. Tribol., 224: 453-479. DOI: 10.1243/13506501JET752

Niu, X., L. Zhu and H. Ding, 2005. New statistical moments for the detection of defects in rolling element bearings. Int. J. Manufactur. Technol., 26: 1268-1274. DOI: 10.1007/s00170-004-2109-4

Palmgren, A. and G. Lundberg, 1947. Dynamic Capacity of Roller Bearings. 1st Edn., Generalstabens litografiska anstalts förlag, Stockholm, pp: 50.

Raptis, K., G. Papadopoulos, T. Costopoulos and A. Tsolakis, 2011. Experimental study of load sharing in roller-bearing contact by caustics and photoelasticity. Am. J. Eng. Applied Sci., 4: 294300. DOI: 10.3844/ajeassp.2009.394.300 
Sayles, R.S., 1995. Debris and roughness in machine element contacts: Some current and future engineering implications. J. Eng. Tribol., 209: 149-172. DOI: 10.1243/PIME_PROC_1995_209_421_02

Wongchai, B., P. Visuwan and S. Chuepeng, 2013. The vibration analysis of diesel engine with hydrogendiesel dual fuel. AJAS Am. J. Applied Sci., 10: 814, DOI: 10.3844/ajassp.2013.8.14

Zaretsky, E.V., J.V. Poplawski and C. R. Miller, 2000. Rolling Bearing Life Prediction-Past, Present and Future. 1st Edn., National Aeronautics and Space Administration, Glenn Research Center, Cleveland, Ohio, pp: 12.
Zotos, I. and T. Costopoulos, 2008. A study on the increase of numerical stability and accuracy of the transfer matrix method. J. Math. Stat., 4: 208-212. DOI: $10.3844 /$ jmssp.2008.308.212

Zotos, I. and T. Costopoulos, 2009. On the use of rolling element bearings models in precision maintenance. Am. J. Eng. Applied Sci., DOI: 10.3844/ajeassp.2009.344.352 